Tõnis Tatar

\title{
THE POSSIBILITY OF A BRIDGE. PERSPECTIVES AND LIMITATIONS OF NEUROAESTHETICS
}

Art can be studied by philosophers, psychologists, sociologists, theologians, computer scientists, educationalists, neuro-scientists, critics and, of course, art historians. Most would agree that although no single perspective alone can offer an exhaustive explanation, the competences, knowledge and methods derived from different fields are nonetheless helpful and necessary in analysing a phenomenon as diverse and complex as art. ${ }^{1}$ Therefore it seems to be in the interest of art historians (aestheticians, critics and artists) to embrace the expertise offered by other fields. This article seeks to throw some light on the possibilities and perils of implementing the knowledge and means from other fields of research, such as evolutionary and neuropsychology, to the understanding of art.

Even Marcel Duchamp, who famously claimed that painters were dumb ('bête comme un peintre'), would hardly have seriously doubted that creation (as well as the reception) of art inevitably occurs with the participation of the brain. Yet for many (especially in art world), the idea of the neurology of art entails has strange and even dangerous implications. While it is generally not difficult to concede that

DOI: https://doi.org/10.12697/BJAH.2019.17.06

1 Oliver Sacks, Musicophilia: Tales of Music and the Brain (London: Picador, 2008), 5. 
neurological processes are responsible for simple emotions, affects or urges, there is a widespread reluctance to accredit the laws of the brain with the so-called higher functions that include creation and experience of art and aesthetic pleasures. We are accustomed to assuming that the value and attraction of art is defined by its very indefiniteness, in the different ways it nurtures, excites and annoys its viewers. ${ }^{2}$ From this perspective it may appear that placing art in the context of the evolutionary development of the human species or analysing it through the means of cognitive neuroscience demystifies or even denigrates art. ${ }^{3}$

On the other hand, the humanities, while holding a traditionally repellent stance toward non-humanitarian input, have, especially since the second half of the $20^{\text {th }}$ century, rather enthusiastically implemented various theories, ideologies and methods from the social sciences. In the psychology of art, the turn towards socio-historical settings in the analysis of the higher cognitive functions was paved by Lev Vygotsky and cultural-historical psychology. ${ }^{4}$ Indeed, while the Kantian concept of art as the domain of disinterested pleasure has been radically criticised, the humanities have (perhaps all too willingly) recognised art as the subject of ideologies and social discourses. One may feel prompted to ask whether and how theories of culture based, for instance, on Marxism or psychoanalysis are more appropriate and functional than those based on evolutionary psychology or studies of the brain.

The humanities and natural sciences are of course differentiated by their distinct methods. As the requirement of empirical verifiability is often unattainable or even undesirable in aesthetics, it may well seem that the objectives and methods of the natural sciences and humanities are indeed incompatible. Brain researcher Gerhard Roth argues that this separation of the spheres of natural and humanitarian interest is reasonable as long as a fundamental difference is assumed between the nonhuman nature and the field of human activities (including culture). According to this view the field of nature is generally consistent with the laws of nature, and Therefore, immutable, predictable, unhistorical and unindividual, while the

2 Semir Zeki, Inner Vision (Oxford: Oxford University Press, 1999), 216

3 Ibidem, 219.

4 Jüri Allik, 'Kunst ja psühholoogia', Looming, 9 (1970), 1393. field of humans, in contrast, is held to be volatile, unpredictable, historical and individual. Naturally, the fact that the human mind and consciousness are indeed natural phenomena hardly renders such an exclusion of human beings from the realm of nature (and studies of natural sciences) defendable. ${ }^{5}$

The sceptical and protective position that the humanities hold over their field is described by Denis Dutton: 'For the usual culture theorist, the picture came to look like this: to be sure, the biological structure of the body - the corpuscles of its blood, its organs, its musculature - were dictated by DNA and RNA. Darwin and the biologists were credited with that much. Culture, however, was completely different. It was a realm of free activity that engraved itself on a mental blank slate: culture was the uncontested domain of the humanities, untouched by biology.' In Dutton's view, an all-embracing ideology of social construction was laid down in the humanities that separated themselves from biological realities. According to these 'blank-slate theories of the mind' not only some, but all of our artistic meanings and value ascriptions derive from history and culture. As to theories of art, it became the general view that meaning, emotion, and aesthetic experience are matters of unconstrained cultural developments completely unrelated to Darwinian evolution and the biology of the brain. According to Dutton this view meshed perfectly with an important aspect of modernist ideology - the belief that our ability to adapt to new kinds of art has no limit whatsoever beauty can reside in any perceptual object, aesthetic pleasure can be taught and art can be anything. ${ }^{6}$

\section{NEUROAESTHETICS, POSSIBILITIES AND LIMITATIONS}

Only recently has a discipline known as cognitive neuroscience of art or more prevalently neuroaesthetics risen to the fore from among the various disciplines that approach the subject of aesthetics using non-humanitarian methods. The rise of neuroaesthetics can be seen as part of a wider explosion of neuroscience that was triggered by the invention of various technological devices, such

5 Gerhard Roth, Aus Sicht des Gehirns (Frankfurt am Main: Suhrkamp, 2015), 228-229. 6 Denis Dutton, The Art Instinct: Beauty, Pleasure, and Human Evolution (New York: Bloomsbury Press, 2009), 204-205. 
as electroencephalography (EEG), functional magnetic resonance imaging (fMRI), and positron emission tomography (PET). The unprecedented possibility of monitoring the brain while it is working allowed neuroscience direct access to the analysis of mental abilities (sensations, thinking, imagination, remembering, planning) as well as affects and emotional states. ${ }^{7}$ Thereby, an alternative nonhumanitarian means of analysing mental processes and experiences (among others creation and reception of art) emerged.

While aesthetics traditionally deals with creation, reception and thinking about arts, neuroaesthetics is more specifically concerned with the role of the brain in these processes. Thus, neuroaestheticians apply neuroscientific methods to problems of aesthetics, such as the general criteria of aesthetic decisions, the common part of pleasures derived from different arts, relationship between aesthetic experience and everyday experience, connection between aesthetic experience and different kinds of knowledge, the problem of the universality and individuality of aesthetic experience, etc.

Neuroaesthetics searches the human brain for universal conditions and laws of art. Here we once again encounter the mind-body problem related to the possibility of explaining the mind using the methods of natural sciences. On the one hand, nothing in the human brain has been found that would contradict the laws and principles of nature. Hence, provided that mental processes originate from the brain, it should be at least in principle possible to understand the relationship between the brain and the mind via natural sciences. On the other hand, in describing the relationship between the biological brain and human mind we encounter a fundamental explanatory rift that lies in the fact that human beings experience states of consciousness differently from the way they experience material things and processes. In other words, the brain and the mind are places where the otherwise rather clear notions of subjectivity and objectivity seem to lose their traction. According to a more optimistic approach (neurophilosophers Patricia and Paul Chuchland) this problem is solvable and it is possible to replace 'everyday psychological' descriptions of states of mind with a more exact neuroscientific terminology. Other philosophers such as Thomas Metzinger and Michael Pauen reject such a 'reductionalist' solution but nevertheless hold a neurobiological explanation of the mind principally possible. Third strand of philosophers such as David Chalmers and Joseph Levine argue that the aforementioned explanatory rift renders the problem of the brain and the mind insoluble. ${ }^{8}$

It must be stressed that neither neuroaesthetics nor other bridging disciplines between humanities and natural sciences can reasonably be expected to replace humanitarian aesthetics. It seems clear their efficiency is at most a complement to the humanitarian discipline. While a multiplicity of perspectives is inevitable in analysing a phenomenon as complex as art it is also important to acknowledge the limitations of different methods. Neuroaestheticians Anjan Chatterjee and Oshin Vartanian break down the experiments in neuroaesthetics into three general systems of neural circuitry: sensory-motor, emotion-valuation, and meaning-knowledge systems. Neuroaesthetics tend to focus on the first two components of this triad, while recognising its short arms in the third department which is rather more culturally determined. ${ }^{9}$ Cognitive neuroscientist Martin Dresler has remarked that while the creation and reception of art depends on an individual and his or her neural processes, the definition or recognition of an object as a work of art (or even more so, a great work of art) hinges on socio-cultural processes that cannot be reduced to the neural mechanisms of the visual system. ${ }^{10}$

Assuming the immutability of the human brain during the last thousand or so years, neuroaesthetic theories regard artistic experiences and judgements throughout history as being commensurate and comparable. The more closely a scientific hypothesis is related to the biological perceptual system, the more we can generalise the results across time. For instance, it can be boldly assumed that the biological conditions of the sensation of colour or movement have not changed in the historical era. ${ }^{11}$

8 Roth, Aus Sicht des Gehirns, 142-143.

9 Anjan Chatterjee, Oshin Vartanian, 'Neuroaesthetics', Trends in Cognitive Sciences, (18) $2014,370-375$

10 Martin Dresler, 'Kunst und Neurowissenschaft', Neuroästhetik: Kunst - Gehirn Wissenschaft, ed. by Martin Dresler (Leipzig: Seemann, 2009), 29

11 Per O. Folgerø, Lasse Hodne, Christer Johansson, et al., 'Effects of Facial Symmetry and Gaze Direction on Perception of Social Attributes: A Study in Experimental Art History',
Frontiers in Human Neuroscience, 10 (2016), 9. 
In criticism of such an approach, a discrepancy between aesthetic judgements over time (e.g., the paintings by van Gogh are valued highly today but not so much in his lifetime) has been pointed out. Therefore, as the argument goes, the relationship between experimental art and its viewer does not conform to the universal principles of psychology and neuronal mechanisms. ${ }^{12}$ While this argument certainly holds a grain of truth, the opposite view, i.e. that historical shifts in art and intercultural differences make it impossible to state any general claims about art, would be equally misleading. Thus, as is so often true in life, in this case the truth also lies somewhere in between.

In defence of his method the neuroaesthetician Vilayanur S. Ramachandran has called reductionism the 'most powerful strategy known to science'. This may hold truth in the context of natural sciences but, as noted, to view the processes of the brain and their products (such as art) in an exclusively biological perspective would be limiting. The human brain is shaped not only by genes (the bottom-up processes), but also by a wealth of past experiences (topdown effects), including something we call culture. Therefore, in order to understand mental phenomena, it is not enough to demonstrate their causal relationships with neural mechanisms, but a satisfactory explanation should also involve non-physical factors (thus making it more difficult to make universal generalisations). Of course, in case of aesthetics this primarily means a knowledge of the history of art. ${ }^{13}$

\section{SOME FEATURES OF THE NEUROAESTHETIC THEORIES OF ART}

At this point, the fundamental principles related to the theories of art need to be recalled. Firstly, no theory of art is capable of satisfactorily explaining of all kinds of art, while each worthwhile theory can, to some extent, explain some kind of art. Secondly, the distinction between the theory and ideology of art is essentially vague and therefore explanations based on art theory cannot be easily separated from value judgements and artistic preferences. Next, I will look into

12 Dresler, 'Kunst und Neurowissenschaft', 29

13 Erich Harth, 'Art and Reductionism', Journal of Consciousness Studies, 11 (3/4) (2004), 11,114 the implications of these axioms related to the theories of art based on natural sciences.

The area of research that aesthetics and history of art cover ranges from the Stone Age to the latest Venice Biennale, the Kasse documenta and the Art Basel fair. There is hardly another field of culture that is characterised by comparable historical ruptures and inner heterogeneity. Indeed, even the most diverse forms of music are linked by their basic format of sound, even the most different forms of dance share the movement of bodies in space, each and every film in the history of cinematography is comprised of something recorded by a camera etc. Meanwhile in (contemporary) art, there is no such common attribute - in the discipline formally known as visual arts the current output does not even have to be visual. The heterogenous assembly of contemporary art works is atomized in between various formats that lack any possible common nominator, apart from their institutional ties (i.e. they are produced by artists, recognized as art by specialists and exhibited in museums and galleries). Thus, when we compare classical painting or modernist sculpture with conceptual installations or performances, the need for different theories becomes quite evident.

Neuroaesthetic theories (as all individual aesthetic theories) do not have an explanatory capacity to cover the entire spectre of art's history and present. Thus, there should be no shame in admitting that brain research and evolutionary psychology have proven impotent in deciphering the conceptualist vogue so prevalent in contemporary art. Conceptual art works tend to be self-referentia and ironic, questioning their very own medium, as well as traditional aesthetic values, to the point where the works of art amount to little more than their idea or concept. Alexander Kranjec suggests the reason neuroaesthetics have largely ignored conceptual art lies in the incompatibility of its methods to the unpacking of the complex layers of intent and reference that define many individual works. ${ }^{14}$

Due to aforementioned methodological difficulties, but perhaps also the natural sciences backgrounds of most writers, neuroaesthetic theories tend to stress the visual nature of art. For instance, the leading neuroaesthetician Semir Zeki also concedes that, based on

14 Alexander Kranjec, 'Conceptual Art Made Simple for Neuroaesthetics', Frontiers in Human Neuroscience, 9 (2015), 3. 
current knowledge, it is almost impossible to say anything beyond the most general about the relationship between brain physiology and the perception of more complex, narrative and representational works. According to Zeki, visual art is largely, though not exclusively, a product of the activity of the visual brain. The function of the visual complex of the brain that coincides with the function of visual art is search for knowledge and constancies in a changing world. To be more precise, visual works of art entail representations of essential features of objects or situations generated by the brain on the basis of all the examples that it has encountered. Therefore, according to Zeki, artists are, in a sense, neurobiologists who without knowing it use artistic means to study the brain and neural processes. All the other functions of art, such as social or psychological function, merely supplement this main function. ${ }^{15}$ While the pretension of having found the underlying principle of all painting is almost certainly overreach, this theory is very applicable to certain forms of modernist painting and sculpture. Indeed, Zeki illustrates his theory with examples of various styles of experimental modernist art that, he argues, correspond to certain areas and functions of the visual brain (e.g., the paintings of Piet Mondrian address area V1 corresponding to horizontal and vertical lines, ${ }^{16}$ the Fauves appeal to area $\mathrm{V} 4$ responsible for reactions to colour ${ }^{17}$ while kinetic art aims at V5 that manages visual signals of movements, ${ }^{18}$ etc.).

In addition to visuality, another feature often prominent in the analyses of art from the natural sciences side is the mimetic function of art - of course, this is also a feature long abandoned by mainstream aesthetics as hopelessly outdated. Neuroanthropologist Merlin Donald has argued that human evolution moved from the 'episodic' life of apes to a 'mimetic' culture of humans. The latter flourished and lasted for tens, perhaps hundreds, of thousands of years before language and conceptual thinking evolved. Donald proposes that mimesis or the power to represent emotions, external events, or stories using gesture, posture, movement and sound is still

15 Zeki, Inner Vision, 2, 8-10.

16 Ibidem, 118-125.

17 Ibidem, 197-204

18 Ibidem, 143-163. 
the bedrock of human culture today. ${ }^{19}$ In similar vein, Denis Dutton a philosopher of art, asserts that human beings are born imagemakers and image-enjoyers. 'Imitation is a natural component of the enculturation of individuals. This is from the creative side: from the experiential side, human beings enjoy experiencing imitations, whether pictures, carvings, stories, or play-acting. ${ }^{20}$

Another prominent aspect is the difference in tonality used by researchers and theoreticians with natural sciences backgrounds to address the qualities of art such as beauty and emotion. In sharp contrast to the dismissing attitude shared by most humanities, neuroaestheticians and other representatives of the natural sciences approach to aesthetics tend to accredit these features with a new meaning. Art has historically and universally striven towards beauty and the expression of emotion, thus these qualities probably have a deeper function in art than just pure cultural contingency. Whereas the prevalent view in modern humanities holds that beauty is arbitrary and superficial, psychologist Nancy Etcoff stresses the irrational and hedonistic essence of the experience of beauty: 'Our body responds to it viscerally and our names for beauty are synonymous with physical cataclysms and bodily obliteration - breathtaking, femme fatale, knockout, drop-dead gorgeous, bombshell, stunner, and ravishing. We experience beauty not as rational contemplation but as a response to physical urgency. ${ }^{21}$

As to the emotions that works of art are capable of capturing, it has been argued they function as 'relevance detectors'. Thus the Darwinian function of expression of emotions is to provide swift appraisals of objects, people, events, and thoughts that represent their value for our own needs, desires, survival, sense of self, and sense of community. ${ }^{22}$ If emotions are indeed a means used by the brain to emphasize what is important, then perhaps the traditional association between arts and emotional values is not just another culturally determined contingency but rather an anthropological characteristic and, indeed, an essential part of human nature. As

19 Sacks, Musicophilia: Tales of Music and the Brain, 268. See: Merlin Donald, Origins of the Modern Mind: Three Stages in the Evolution of Culture and Cognition (Cambridge, MA: Harvard University Press, 1991).

20 Dutton, The Art Instinct: Beauty, Pleasure, and Human Evolution, 33

21 Nancy Etcoff, Survival of the Prettiest. The Science of Beauty (New York: Anchor, 2000), 9.

22 G. Gabrielle Starr, Feeling Beauty. The Neuroscience of Aesthetic Experience (Cambridge, MA; London: The MIT Press, 2015), 21-22. literary scholar G. Gabrielle Starr has put it: 'I believe that aesthetic experience helps us understand a world we cannot fully predict, helps us value things that are new and learn how to compare what seems, at first, incommensurable. ${ }^{23}$

From the viewpoint of evolutionary psychology and neuropsychology, culture, including art, is not merely a cultural convention projected on the blank sheet of the human mind, but also a reflection of human nature as represented by evolution in the structure and functioning of the brain. This applies not only to the conditions of creation, but also the reception and judgement of art. Social psychologist Jonathan Haidt has identified a complex association of universal emotions that he calls 'other-praising' emotions. They are not local manifestations of basic affects, such as joy, curiosity or pleasure in amusement, but a specific and irreducible family of human emotions in their own right. These other-praising emotions include gratitude for the actions of others, admiration for the excellence in another person, particularly for displayed skills, and a heightened sensibility that Haidt calls elevation. Haidt sees these emotions as an innate 'response to non-moral excellence'. Presumably they are adaptations by the human mind to social relationships. ${ }^{24}$ Built into human sociality they are sources of a distinct pleasure of admiration, and as such, the reasons we take so much joy in a masterfully conceived and realised work of art.

As already mentioned above, the approaches to art based on the natural sciences tend to be more neutral and distanced from its object compared to the usual humanist methods. Instead of stressing the historic and local differences and cultural exceptions, researchers with natural sciences background tend to search for the universal qualities of art. According to Dutton, the universality of art and artistic behaviours, their spontaneous appearance every where across the globe and throughout recorded human history, and the fact that in most cases they can be easily recognized as art across cultures, suggest that they derive from a natural, innate source: a universal human psychology. In this respect, the universality of art resembles another persistent human proclivity: language use. ${ }^{25}$

23 Starr, Feeling Beauty. The Neuroscience of Aesthetic Experience, 26-27.

24 Dutton, The Art Instinct: Beauty, Pleasure, and Human Evolution, 190-192.

25 Ibidem, 30. 


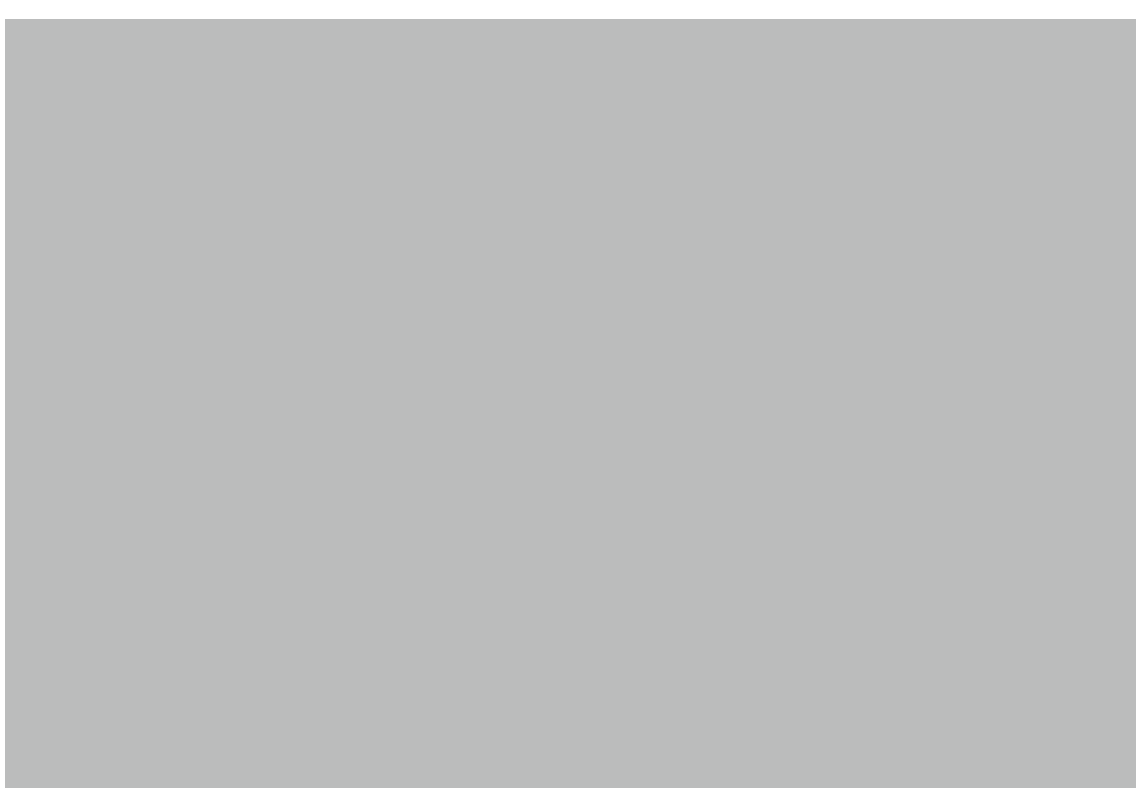

Fig. 2. Ülo Sooster, Eye in the Egg. 1962. Tartu Art Museum.

Humanist aesthetics have reacted to such ideas with a degree of astonishment and reproaches of reactionary conservativism. William P. Seeley, a philosopher of art and cognitive scientist, has asserted that he is surprised 'by the degree to which the folks on the neuroscience side of these endeavours are committed to a core aestheticism. In this regard the term "neuroaesthetics" isn't just a name. It reflects an ideological bias about the nature of art. And this is a sticking point. ${ }^{26}$ The philosopher of art John Hyman has gone as far as labelling ideas expressed by neuroaestheticians Ramachandran and Hirstein as 'the Baywatch Theory of Art', claiming that it 'doesn't distinguish between a work of art and the kind of object that it represents. For example, if it doesn't distinguish between a sculpture that represents a woman with big breasts and a woman with big breasts. ${ }^{27}$

26 William P. Seeley, 'What Is the Cognitive Neuroscience of Art... And Why Should We Care?', American Society for Aesthetics, 31 (2) (2011), 2.

27 John Hyman, 'Art and Neuroscience', Beyond Mimesis and Convention, ed. by Roman Frigg, Matthew C. Hunter. Boston Studies in the Philosophy of Science 262 (Dordrecht; Heidelberg;
London; New York: Springer, 2010), 250.

\section{TOWARDS A BIOLOGICAL THEORY OF ART}

If we were to agree that art is not a purely arbitrary and conventional socio-cultural construction (a blank sheet to be filled with just about anything), and instead acknowledge that it is a universal phenomenon transcending cultures and historical periods, then we would have to consider the possibility that human beings accommodate an innate complex of conditions of artistic activities. Now, an adequate and inclusive description of such conditions (which we might call the 'art instinct') would amount to nothing less than a biologically based theory of art that would provide a neutral ground for future (humanist) analyses of art.

However, it should be underlined once more that an objective theory of art that draws on empirical and evolutionary psychology and neuroscience is not to be juxtaposed with the humanist theories of art. The fact that art as a universal phenomenon springs from a general innate complex of skills and propensities does not contradict the fact that society, culture, art history and the art world also exert a remarkable influence on the organisation of the broad spectre of aesthetic tastes and artistic styles. Indeed, we could say that art is largely a cultural affair, but the instinct it strives to answer is of the natural world. ${ }^{28}$ Therefore, it is not possible to understand art as a human practice without understanding both.

Having stressed the mutual compatibility of humanist and scientific approaches to art, there is one influential theory of art that appears to be irreconcilable with theories of natural background. Unfortunately, this is also the most powerful one in today's art world, namely the institutional theory of art that implicitly underlies the entire contemporary paradigm of art. It can be assumed that some of the reasoning for the sceptical or outright confronting attitude shared by most mainstream humanitarian discourse is hidden behind this conflict.

The institutional theory of art was first formulated in the 1970s by George Dickie, who famously claimed that art is exclusively defined by institutional forces operating in the art world. Historically this theory emerged as an answer to the avant-garde movements of the early $20^{\text {th }}$ century, and offered a way to rationalise these extremely

28 Dutton, The Art Instinct: Beauty, Pleasure, and Human Evolution, 206. 


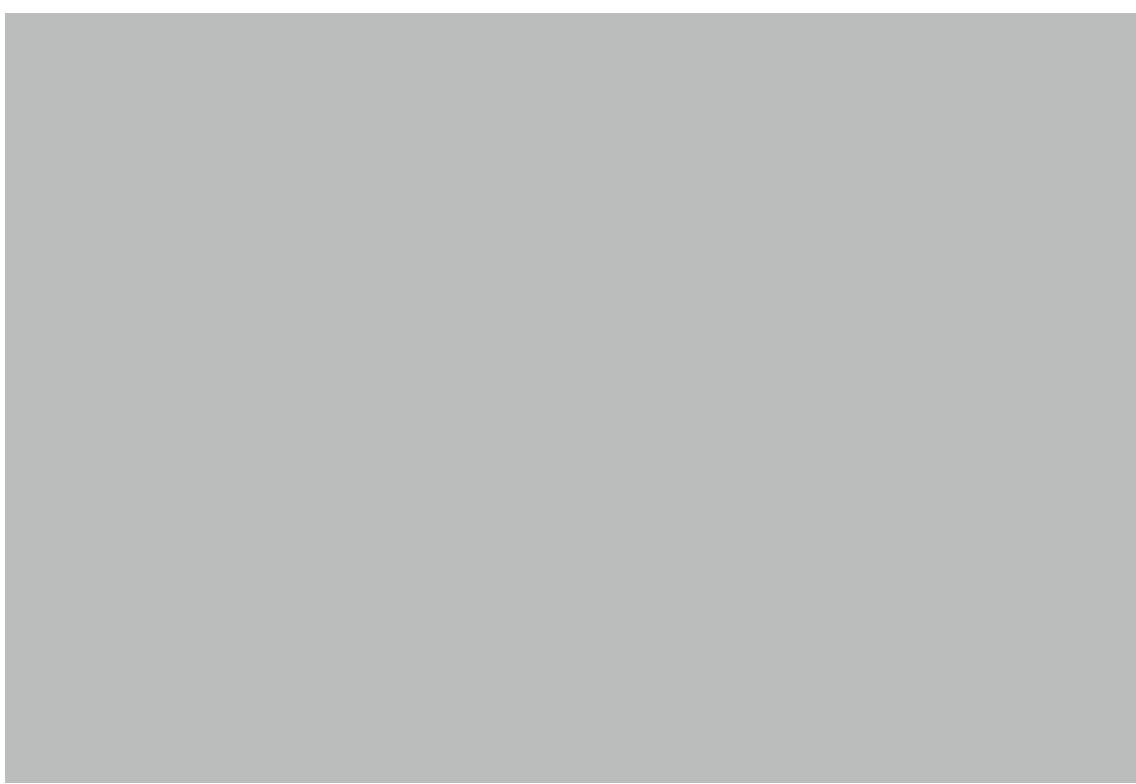

Fig. 3. Ülo Sooster, Torso. 1967. Tartu Art Museum.

eccentric and irregular phenomena as works of art in a way, that in its cynical simplicity, bordered on elegance. Accrediting all artistic and aesthetic phenomena exclusively to arbitrary institutional decisions, the institutional theory of art leaves no room to embrace the anthropological or neurobiological aspects that may underlie artistic practices. If art is indeed solely an arbitrary construction executed by cultural institutions, then it is clearly superfluous to question whether things like Duchamp's ready-mades qualify as works of art at all. According to institutional theory they must be art for the simple reason that the institutions of the art world have widely acknowledged them as such.

The obvious conflict between an upside-down toilet utensil placed on a podium and the intuitive conception most people hold of a work of art are dismissed as little more than ignorance and inertia of the backward public. According to Dutton, we should at least be suspicious of this uncoupling of understanding of art from empirical psychology. While somewhat successfully explaining why objects like the 'Fountain' can, under certain circumstances, be recognized as art, institutional theory remains tight-lipped and inefficient in explaining the overwhelming majority of art created by different civilisations in different periods of history. In words of Dutton, it is odd that against this glorious availability philosophical speculation about art has been inclined toward endless analysis of an infinitesimally small class of cases, provocations such as Duchamp's ready-mades or John Cage's 4'33". The obsession with accounting for art's problematic outliers, while intellectually challenging, has left aesthetics ignoring the wide and diverse centre. 'From Lascaux to Bollywood, artists, writers, and musicians often have little trouble in achieving crosscultural aesthetic understanding. The natural centre on which such understanding exists is where theory must begin. ${ }^{29}$

As Dutton cleverly points out, the glaring stringency of the institutional theory of art is even accidentally disclosed by its author George Dickie. Arguing that art is defined by its institutions and their attendant cultural practices, Dickie notes: 'That tradition has run very thin at times and perhaps even ceased to exist altogether during some periods, only to be reborn out of its memory and the need for art.' Alas, the man behind the institutional theory himself momentarily lets down his guard and inadvertently reveals there is also a thing such as a 'need for art' and that this need is, in fact, so fundamental that it precedes the institutions of art and guarantees its continual reinvention whenever it lapses. Why Dickie does not elaborate on such an important phenomenon remains a mystery but according to Dutton, it is indeed this very necessity for art - actually a certain set of capacities, propensities and preferences evolved mainly during the Pleistocene epoch - that forms the common grounds of all arts. ${ }^{30}$

Even with the institutional theory of art itself being quite dismissive of other theories, the situation in the arts that it fosters can be subordinated to neuroaesthetic analysis. Chatterjee references a brain imaging study where people were shown patterns that they thought were taken from museums or generated by computers. There was greater activity in the participants' medial orbitofrontal cortexes (i.e. the location known to manage rewards) when they were shown images that they thought were in museums (compared to when they

29 Dutton, The Art Instinct: Beauty, Pleasure, and Human Evolution, 4, 50-51.

30 Ibidem, 40. 
were told they were not). Thus, we can reasonably conclude that rewards are modulated by context, information actually changes the emotional experience, and aesthetic experience is affected by knowledge. ${ }^{31}$ While this finding may be interpreted in various ways, it certainly helps us understand why people are willing to put up with (or even take genuine pleasure in) the excesses of avant-garde and contemporary art.

A more positive example of synthesis between the humanities and natural sciences can be found in Semir Zeki's neuroaesthetic interpretation of Clive Bell's theory of significant form. In his 1914 book called Art, Bell famously postulated the existence of a universal and intercultural aesthetic feeling. This specific feeling is aroused by the formal qualities (lines, colours and their combinations) in works of art, which he calls significant forms. Zeki argues that if Bell is indeed right and aesthetic emotion is, on the one hand, subjective and, on the other hand, independent of culture and knowledge we should ask whether this feeling is bound to a specific area or pathway in the brain. Experiments undertaken to locate a correlate for the experience of beauty in the brain have pointed to medial orbito-frontal cortex (mOFC) of the frontal lobes. This area of the brain becomes active when subjects (regardless of cultural background) experience beauty. The experience of beauty also activates other areas of the brain, but as far as is known, mOFC is the only area that becomes active irrespective of whether the source is visual, musical or mathematical. Thus it can be understood to be the representation of beauty in the brain on a somewhat abstract level. Also, a correlation has been established between the level of activation of mOFC and respondent's evaluation of intensity of his or her experience. According to Zeki, this would provide an answer to a fundamental problem of aesthetics, namely, the possibility of objective aesthetic judgements ('objective' referring here to the detectability and quantifiability of the mOFC activity). ${ }^{32}$

31 Anjan Chatterjee, 'Where There Be Dragons: Finding the Edges of Neuroaesthetics' Criticism and Theory of the Arts, 31 (2) (2011), 5. See: Ulrich Kirk, Martin Skov, Oliver Hulme, Study', NeuroImage, 44 (2009), 1125-1132.

32 Semir Zeki, 'Clive Bell's "Significant Form” and the Neurobiology of Aesthetics', Frontiers in Human Neuroscience, 7 (November 2013), 1-3.

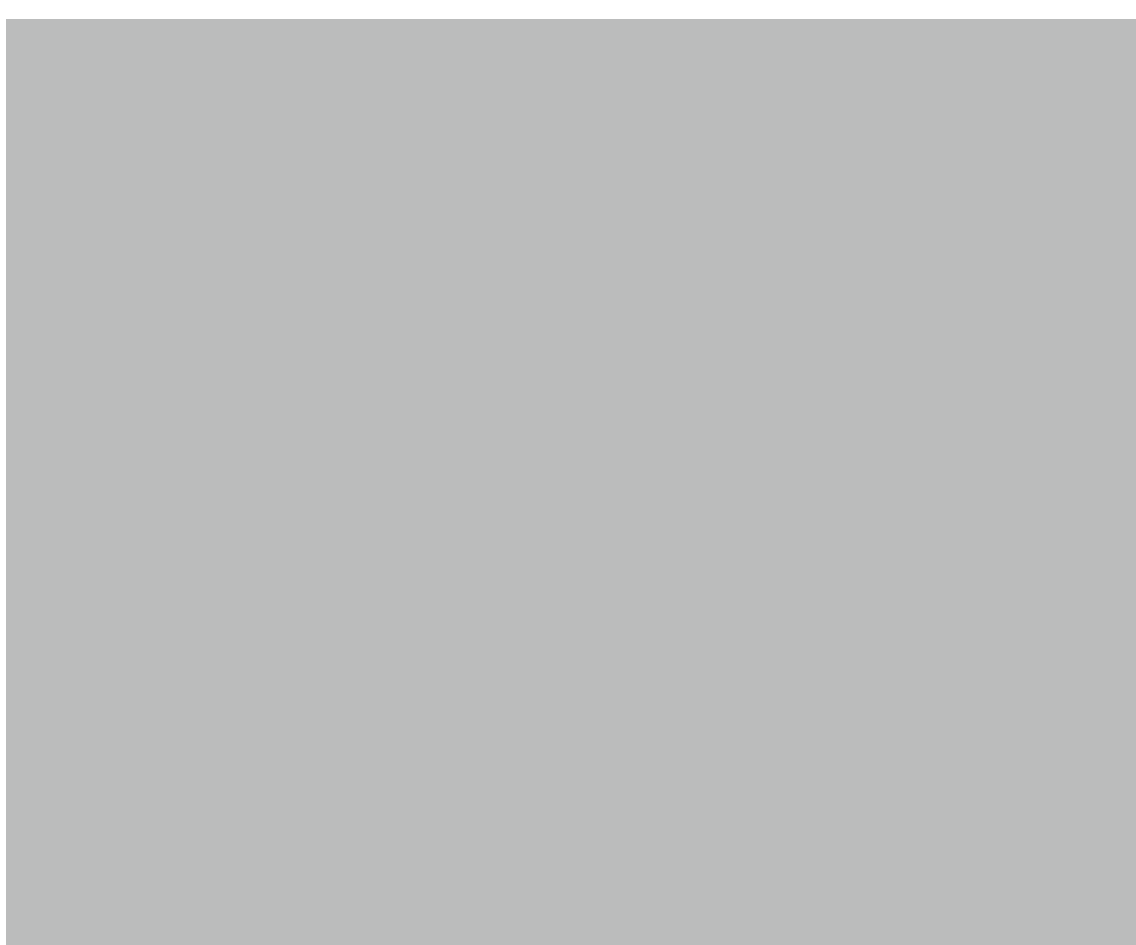

Fig. 4. Ville-Karel Viirelaid, Waiting for a Curator. 2006. Tartu Art Museum.

Zeki also argues that the significant form defined by Bell as lines, colours and their combinations is too narrow a concept. In his words a term better suited to our knowledge of the visual complex would be 'significant configuration' - a term that would also comprise other aesthetically appreciated attributes, such as faces, bodies, and motions. Placing Bell's theory in a neuroaesthetic framework Zeki argues that the somewhat mystical laws of significant form actually denote preferred activation patterns of certain areas of visual brain. Thus, the skill (or 'genius') of an artist capable of creating 'significant forms' (or 'configurations') can be rephrased in natural sciences terminology as an ability to create forms that activate these areas in an optimal or specific manner that differs from their activation through stimuli that are not 'significant forms' (or 'configurations'). Zeki speculates that perhaps it is only when activated in this specific 
manner that the sensory areas of the brain give rise to aesthetic emotion. ${ }^{33}$

\section{IN CONCLUSION: AN HYPOTHESIS}

To conclude I would like to offer a general hypothesis concerning modernist and avant-garde art and the rules of the brain. Elaborating on his concept of the 'art instinct' Denis Dutton offers a twelve-part set of core items that reflect the realm of human experience, which people, regardless of their cultural background, have little trouble identifying as artistic. This cluster of supposedly cross-cultural features of art includes: (1) direct pleasure; (2) skill and virtuosity; (3) style; (4) novelty and creativity; (5) criticism; (6) representation; (7) special focus; (8) expressive individuality; (9) emotional saturation; (10) intellectual challenge; (11) art traditions and institutions; (12) imaginative experience. According to Dutton this list identifies the most common 'surface features' of art that are observed across the world, and thus, 'presents in its totality a definition of art: any object that possessed every feature on the list would have to be a work of art. ${ }^{\prime 34}$

I would suggest these characteristics to be projected onto the general tendencies of art in the modernist era (from Paul Cézanne to the conceptual art of the 1970s). As a possible starting point for future analyses I would propose the following idea - the art of the modernist period was in fact an unconscious yet systematic negation of the conditions of art prescribed by the laws of the brain. Even after modernist culture was discarded in the early seventies and replaced by a more inclusive and less dogmatic culture of postmodernism, this paradigm of a blank-slate view of culture has implicitly endured in the art world in the form of an institutional theory of art. To put it most simply - if institutionalists and cultural constructivists are right and the human mind and culture are merely blank sheets to be filled by absolutely anything (and the seemingly universal characteristics such as those listed by Dutton are merely arbitrary cultural contingency), then there is indeed no need to study the evolutionary or neuropsychological

33 Zeki, 'Clive Bell's "Significant Form" and the Neurobiology of Aesthetics', 6-9.

34 Dutton, The Art Instinct: Beauty, Pleasure, and Human Evolution, 51-61. foundation of art. But if we have doubts, as I suspect many of us do, then one of the challenges in this early phase of the biologically and psychologically fundamented analysis of art should be to throw light on this inherent and ideological bias, which is deeply rooted in the humanistic discourse of arts.

Tõnis Tatar: The Possibility of a Bridge. Perspectives and Limitations of Neuroaesthetics

KeyWORds: NeUROAESTHETICS; BRAIN; BEAUTY; INSTITUTIONALISM; MODERNISM

\section{SUMMARY}

In the traditional study of humanities non-humanitarian input into the study of culture has usually been rejected. According to humanist theories, only the meanings and values derived from history and culture can be attributed to art. Recently a discipline known as neuroaesthetics has risen to the fore from among the various disciplines that use non-humanitarian methods to approach the subject of aesthetics. Triggered by the invention of various technological devices (EEG, fMRI, PET), neuroaesthetics is now being used to tackle the role of the brain in the processes of creation, reception and even thinking about arts.

When introducing new perspectives, such as neuroaesthetics, it is important to acknowledge the limitations of the different methods. A narrow reductional approach to art and the brain clearly does not suffice - a satisfactory explanation must also involve non-physical factors, such as knowledge about the history of art. On the other hand, as with any theoretical approach, the explanatory capacity of neuroaesthetics varies when applied to different kinds of art. Neuroaesthetic theories tend to stress the visual, mimetic and emotional nature of art, often associating artistic features with the activity of the visual brain as well as evolutionary psychology.

Instead of stressing historic and local differences and cultural exceptions, researchers with a natural sciences background tend 
to search for the universal qualities of art. This appears to be irreconcilable with the institutional theory of art that implicitly underlies the entire contemporary paradigm of art. It can be assumed that some of the reasoning behind the sceptical attitude shared by most mainstream humanitarian discourse is hidden in this conflict. It can even be claimed that, under the banner of institutionalist ideas, the art of the modernist period constituted a systematic negation of the conditions of art prescribed by the universal qualities of art based on the laws of the brain. Therefore, one of the challenges in this early phase of the biologically and psychologically based analysis of art should be to shed light on this inherent and ideological bias that is deeply rooted in the humanistic discourse of arts.

\section{CV}

Tõnis Tatar, PhD (b. 1980) is a lecturer in the Department of Art History at the University of Tartu. His main research topics are Estonian art history during the Soviet period, 20th century theories of art, and more recently neuroaesthetics. Previously he has worked at the Tartu Art Museum where he curated a number of exhibitions. 